\title{
Non-traditional applications of fire in fossil preparation
}

\author{
Matthew A. Brown and Casey M. Holliday
}

\begin{abstract}
Fossils have been collected from the field in plaster and burlap field jackets for more than a century. These jackets support and protect the contained fossils until they can be exposed under controlled conditions in the laboratory. The challenging nature of field work and complications caused by limited time, adverse weather, or supply shortages often produce suboptimal jackets that are less protective or difficult to remove. Often, the growth of vegetation through rock and fossils or poorly consolidated sediments compromises the stability of the jacket contents. In such cases, traditional methods of field jacket removal and fossil preparation can cause damage or destruction of the fossils within. We experimented with controlled application of flame to burn away organic materials from field jackets to facilitate safer extraction of sauropod fossils from the Late Cretaceous of Madagascar. To remove the field jacket, acetone was applied to burlap as an accelerant and then ignited with a propane torch. Combined with scoring from a utility knife, this caused the jacket to slowly weaken to the point of pliability and allow safe removal. Direct flame was also applied to plant roots infiltrating the jacket to remove them without causing vibration and mechanical damage within the specimen. Experimentation showed that with monitoring, temperatures did not reach levels that would damage the specimens through thermal shock or discoloration. Subsequent applications of these techniques demonstrate that they can be applied safely when specimens would be destroyed using more conservative methods.
\end{abstract}

Matthew A. Brown. Texas Vertebrate Paleontology Collections, The University of Texas at Austin, Austin, TX, USA., matthewbrown@utexas.edu

Casey M. Holliday. Department of Pathology and Anatomical Sciences, University of Missouri, Columbia, MO, USA and Texas Vertebrate Paleontology Collections, The University of Texas at Austin, Austin, TX, USA. hollidayca@health.missouri.edu

MAB ORCID: https://orcid.org/0000-0002-2713-1161

CMH ORCID: https://orcid.org/0000-0001-8210-8434

Keywords: fossil preparation; conservation; field methods; fire; paleontological methods

Submission: 1 January 2021. Acceptance: 23 May 2021.

Brown, Matthew A. and Holliday, Casey M. 2021. Non-traditional applications of fire in fossil preparation. Palaeontologia Electronica, 24(2):a22. https://doi.org/10.26879/1149

palaeo-electronica.org/content/2021/3308-fire-in-fossil-preparation

Copyright: June 2021 Society of Vertebrate Paleontology.

This is an open access article distributed under the terms of the Creative Commons Attribution License, which permits unrestricted use, distribution, and reproduction in any medium, provided the original author and source are credited.

creativecommons.org/licenses/by/4.0 


\section{INTRODUCTION}

"In a time when dinosaurs walked the earth; when the land was swamp and caves were home; in an age when prize possession was fire, to search for landscapes men would roam." (Harris et al., 1983).

The fossilized remains of animals and plants are commonly excavated from the field in plaster and burlap containers called field jackets, a technique first developed in the late nineteenth century (Brinkman, 2010:46). A well-designed and properly implemented field jacket protects fossils for transport and storage, allowing for more controlled excavation in the laboratory. However, unpredictable field conditions often create challenges that cannot be overcome by standard practice, and innovation is required to ensure the safety of the specimen, both in the field and in the laboratory. Here we detail two emergent applications of fire in the vertebrate paleontology preparation laboratory. First, to aid in the removal of field jacketing material, and second, during preparation within the field jacket to mitigate potential damage caused by plant roots piercing the rock matrix and fossil.

During the excavation of fossils, the surrounding rock matrix is removed by trenching around the specimen and adjacent matrix. Fragile, exposed fossil material is consolidated with a solution-based adhesive. Then a separator layer, typically of wetted tissue paper, newspaper, craft paper, or toilet paper, is applied to the fossil and matrix to protect them from the jacketing material. Burlap strips saturated with wet plaster are then wrapped around the separator and fossils for support and allowed to harden, forming the plaster jacket. Ideally, enough rock is left in close contact with the bone to provide support for the more fragile fossil remains during their journey from the field back to the museum collection (Hermann, 1909; Camp and Hanna, 1937; Langston, 1948; Auffenberg, 1967). The completed field jacket contains the excavated specimen enclosed within its source matrix and allows for final removal of rock from the bone surface in the controlled environment of a fossil preparation laboratory.

The basic technique for making field jackets has remained unchanged since its inception, although the materials for field jacket construction have evolved, beginning with flour paste and burlap treated with toxic mercuric chloride for pest control (Hermann, 1909:285), and in recent years polyester filter foam has replaced burlap (Cavigelli, 2008). Expanding urethane foam has sometimes been used with a separator of aluminum foil (rather than paper separator) to replace plaster and burlap (Carreck and Adams, 1969; W. Amaral, personal obs.). Polyurethane resin and fiberglass bandages have been substituted for plaster and burlap, especially in high latitudes where water in plaster would freeze before curing (Cheney, 1988).

Numerous scenarios can compromise the jacketing process and jeopardize the integrity of the block. When supplies of proper materials run low, field jackets have been improvised using clothing or towels, and other common liquids (e.g., sports drinks, beer) have been tested as substitutes for water (Birthesiel, 2015:91). Adverse weather (e.g., freezing temperatures, rain, or humid conditions) can affect the set time of plaster, or necessitate removing the block from the field site before the plaster has completely cured. Field jackets that are moved too soon can result in soft, flimsy or brittle cradles that contain the fossils, but do not protect them. Reinforcement is sometimes added to a jacket, forming an external armature, including carry-handles or an integrated litter made of locally available scrap material, like old fence posts, dead tree branches, broken tool handles, etc.

Finally, the contents of jackets can extend beyond matrix and fossil, particularly when fossils and their surrounding matrix lie within zones of bioturbation and soils. Insect nests, burrows, natural clefts, moisture, as well as plant roots and fungus can destabilize fossils and their entombing plaster jackets and cause challenges during preparation. Minor damage to fossils caused by roots is evidenced by mechanical and chemical traces on bone surfaces, including formation of grooves and discoloration (Bader et al., 2009; Francischini et al., 2020). Major damage occurs when roots penetrate and grow within or through fossils, which is exacerbated during excavation and preparation (Figure 1). Occasionally, multiple extrinsic and intrinsic factors impact the quality of a jacket and its contents concurrently, requiring new preparation techniques.

Here we describe the use of fire for removing tightly conforming field jackets and plant matter from fragile fossil specimens. The use of fire in the fossil preparation laboratory is rare. Nocera (1955) experimented with direct application of flame to fossils to remove gypsum. Carrol et al. (1972) and Baird (1978) describe the use of fire in the field to rapidly dry consolidants in wet environments by burning off solvents, a technique that was further modified by Tanke (2014). Brusatte (2018:287) figures $\mathrm{M}$. Norell using burning gasoline to drive the 

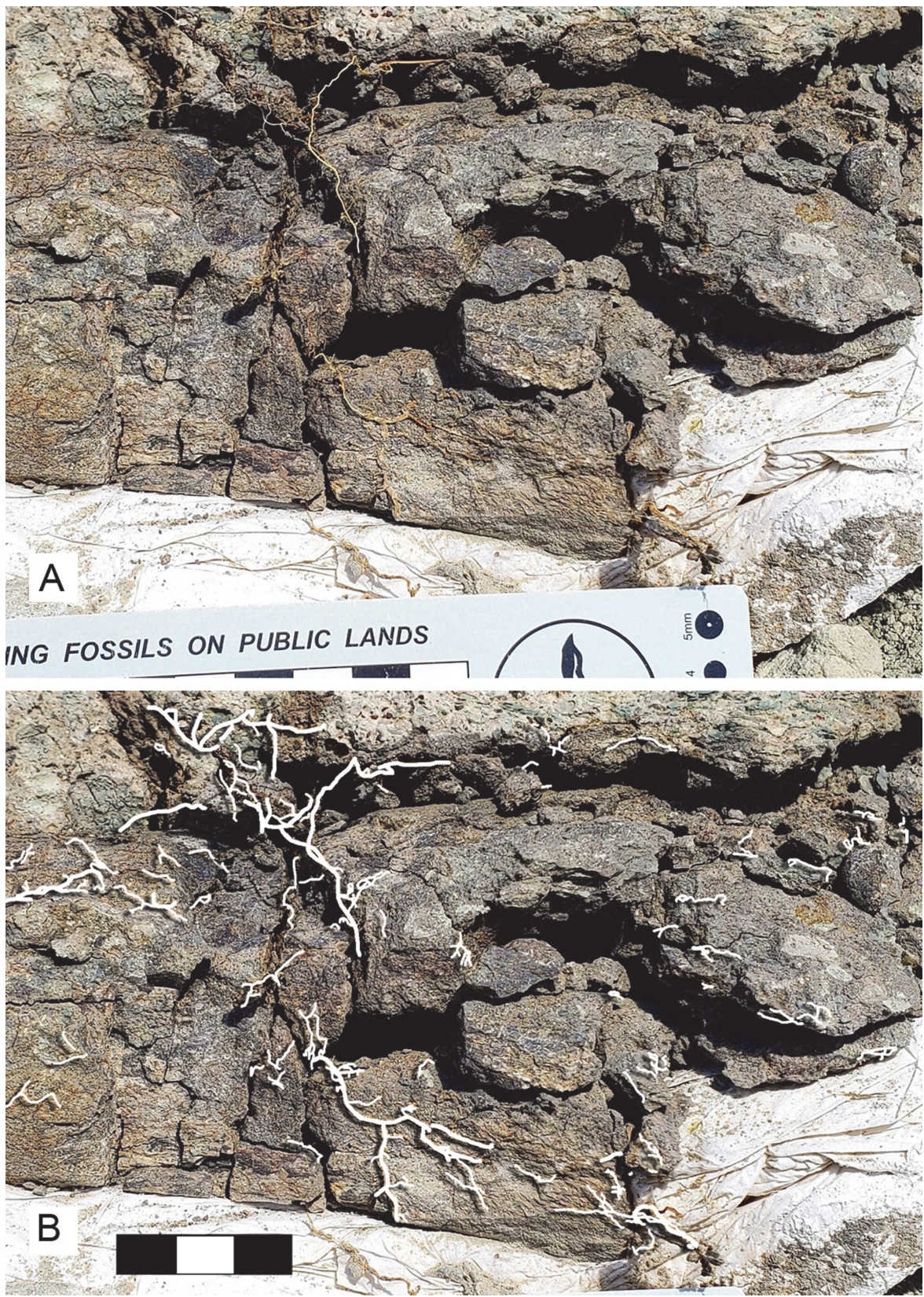

FIGURE 1. A. A fossil in the field subsequent to flipping the jacket shows the extent of root growth across the surface of the bone, and infiltrating the bone and rock (MWC 9874). B. The same specimen, with the root system highlighted in white to better illustrate the pervasiveness of the root network.

moisture out of a plaster field jacket in wet conditions. However, no study to date has described the direct application of fire for removing jackets and plant roots from fossilized bone.

\section{MATERIALS AND METHODS}

Institutional abbreviations. DAK, The Field Museum's Walt Disney World Animal Kingdom Fossil Preparation Laboratory, Lake Buena Vista,
Florida, USA; FMNH, The Field Museum, Chicago, Illinois, USA; MWC, Museums of Western Colorado, Grand Junction, Colorado, USA; MOR, Museum of the Rockies, Bozeman, Montana, USA; PEFO, Petrified Forest National Park, Petrified Forest, Arizona, USA.

The methods described here were first explored in 1999 by the authors at the Field Museum's satellite Walt Disney World Animal King- 

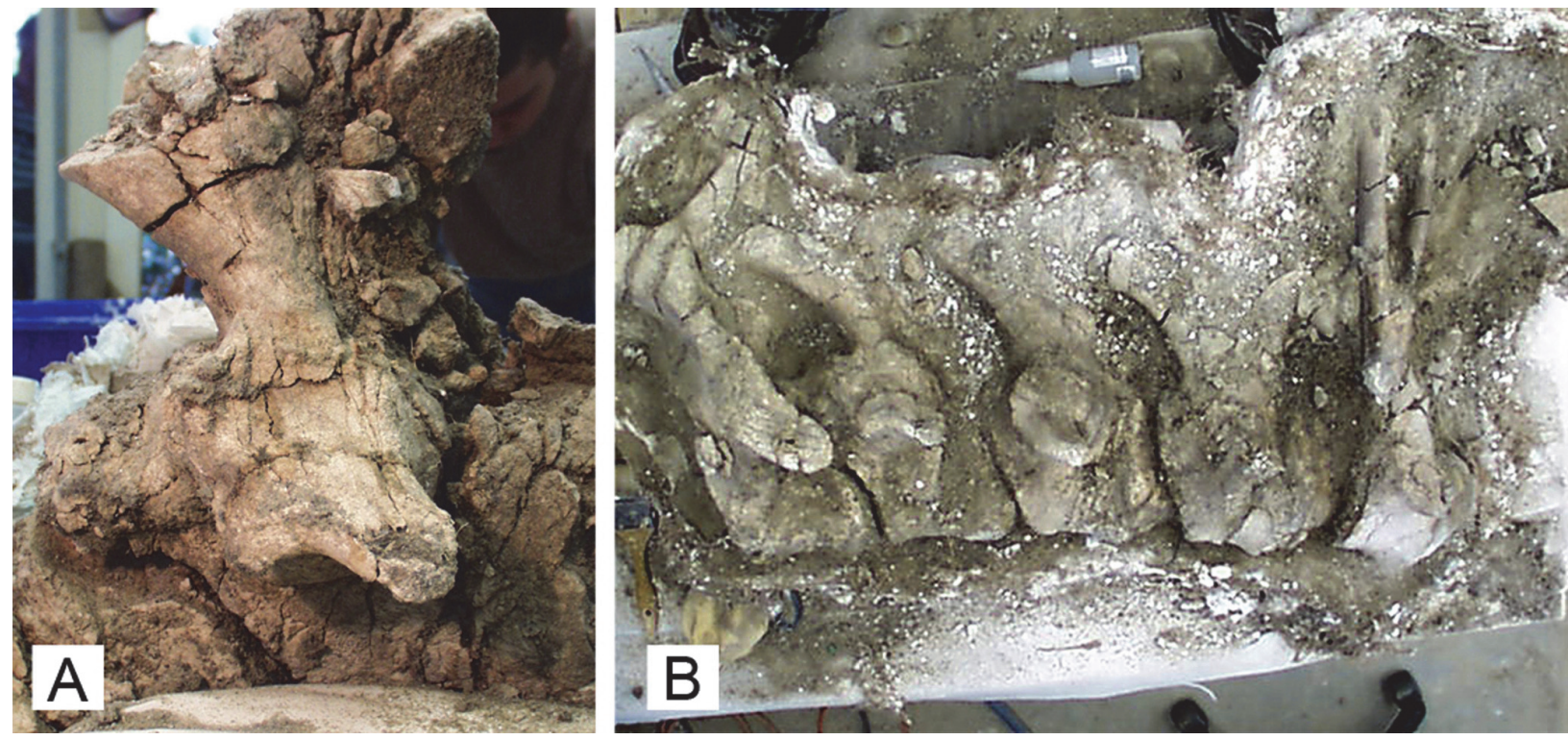

FIGURE 2. A. Field jacket \#98104, containing two anterior caudal vertebrae. Parts of both vertebrae are visible, showing the extensive fracturing of the vertebrae. Most of the roots have been removed at this point, but some remain faintly visible as "whiskers." However, photo quality is poor due to the low resolution of digital cameras in use at the time. B. Field jacket \#98011, containing five articulated caudal vertebrae and two chevrons. This figure shows the broken nature of the fossils in the field jacket, as well as how closely the jackets conform to the bone with little or no matrix in between, especially along the dorsal and ventral aspects.

dom Fossil Preparation Laboratory (DAK). Firebased preparation was applied to fossils collected from the Cretaceous Maevarano Formation of Madagascar by a Stonybrook University team in 1998 and reposited at The Field Museum (FMNH).

\section{Specimens}

The specimens under preparation at the DAK facility included approximately 30 bones of a then undescribed titanosaur (Malagasy Taxon B of Curry Rogers, 2009), now Vahiny depereti (Curry Rogers and Wilson, 2014), which consisted of partially-articulated and disarticulated postcranial skeletal remains preserved in a loosely cemented, finegrained sediment (Rogers, 2005). These specimens were excavated from Facies 2 of the Anembalemba Member, Maevarano Formation, Quarry MAD93-18. Fossil preservation ranges from very good, exhibiting solid surficial integrity and only marginally diagenetically altered structure, to heavily weathered, exhibiting poor separation between matrix and bone and thoroughly shattered fossil material. Rogers (2005:299) interprets this differential weathering of MAD93-18 specimens as the result of multiple localized accumulation events deposited over time, noting inconsistency with damage due to long distance transport. Bone color was mostly very pale orange (10YR $8 / 2$ ), darkening to pale yellowish brown (10YR 6/2) and moder- ate yellowish brown (10YR 5/4) (Munsell Color, 2014). Several regions of fossil elements had a layer of carbonate overlying the bone surface, between which there was poor separation, and often a hard, thick $(\sim .5 \mathrm{~cm}-2 \mathrm{~cm})$ crystalline carbonate deposit was present on the bone. Specimens typically had thin-walled jackets enclosing closely-prepared fossils that lacked separator layers. Thus, either plaster or toilet paper is often directly adhered to the fossils requiring careful preparation in the laboratory with solvents and air scribes. Additionally, plant roots ranging from a few millimeters to $1-2 \mathrm{~cm}$ in diameter were found growing through the matrix and in particular, the fossils themselves. Some jackets had been damaged during transport and plaster and contents were crushed.

Field \#98104. Field jacket containing two anterior caudal vertebrae, missing the right transverse processes and neural spines (Figure 2A). All pre- and postzygopophyses were present and the left transverse process of the anteriormost vertebra was complete. Both specimens were heavily fractured with large roots growing through them. Preservation of overall morphology was generally excellent.

Field \#98011. The field jacket contained five articulated caudal vertebrae and two chevrons (Figure 2B). The preservation was poor except for the neural spine of the anteriormost vertebra and the 
entirety of the posteriormost vertebra. Preservation of cortical bone surface varied from good to poor and the bone was very soft, porous, and heavily fragmented. The vertebrae were deformed laterally after deposition, and jacketed very loosely during collection. The anteriormost four vertebrae were deteriorated in the interior of the centra, infilled with poorly-consolidated gray sand, and had complex root systems growing throughout. Roots were approximately $1 \mathrm{~cm}$ or larger. The anteriormost vertebra had collapsed ventrally and smashed a 3 $\mathrm{cm}$ margin between the neural spine and centrum and remains in two pieces.

\section{Preparation}

Whenever possible, the Vahiny depereti specimens were mechanically prepared following standard laboratory methods (e.g., Rixon, 1976; Leiggi and May, 1994) using Aro and Chicago Pneumatic air scribes, dental scalers, and toothbrushes. Specimens were consolidated and repaired using Rohm and Haas Paraloid B-72, Aron Alpha Type 201 Ethyl 2-Cyanoacrylate, Devcon five-minute epoxy, and WEST System 105 marine epoxy. Fire-aided preparation techniques were used during complicated scenarios as described herein. Preparation was documented with a sub-megapixel Sony Mavica digital camera. Consequently, photograph quality is poor.

Field jacket removal. Fire-aided preparation was first applied to a field jacket containing two anterior caudal vertebrae within jacket \#98104 (Figure 2A). During excavation, much of the surrounding matrix had been removed from around the bones to reduce the size and weight of the field jacket, followed by application of a thick $(\sim 2-3 \mathrm{~cm})$ and tightly conforming plaster and burlap field jacket. The jacket was wrapped tightly around the neural spines and left transverse processes of the articulated vertebra, with little to no matrix buffer between the bone and jacket. The mechanical lock created by the conforming plaster exerted considerable leverage on the bases of the processes when moved, such that conventional attempts at removing the plaster with a razor blade and Stryker 840 cast cutting saw resulted in fragmentation of the fossil and grinding of broken elements against one another. This combination of circumstances resulted in extremely crumbly bone that was very difficult to consolidate with the jacket in place. Removal of the field jacket in the laboratory by traditional means was thus impossible without significant damage to or destruction of the fossil material.
As a last resort, the authors experimented with fire as a tool for jacket removal. First, the surface of the plaster was scored in a cross-hatching pattern with a utility knife to expose the underlying burlap, then acetone was applied to the burlap. When ignited with a butane utility lighter (Scripto ${ }^{\circledR}$ Aim 'N Flame ${ }^{\circledR}$ ) or Bernzomatic ${ }^{\circledR}$ propane torch, most of the burlap combusted, allowing the next layer of plaster to be similarly scored with the utility blade and scratched away. Successive layers of burlap were subsequently burned away, until the remaining layers of the jacket were pliable enough to remove by gently peeling it back from the underlying bone. As the jacket was removed, consolidant was applied to the freshly exposed and friable fossil surfaces.

Vegetation removal. Field jacket \#98011 (Figure 2B) was thoroughly infiltrated with the roots of modern vegetation. These root systems penetrated the fossils, taking advantage of pre-existing cracks in the bone, as well as propagating new pathways and further breaking the fossil apart. The roots were dry, tough, and grew to $1-2 \mathrm{~mm}$ in diameter and upwards of $2 \mathrm{~cm}$. Consequently, the root system effectively tied all the fossils and matrix within the block together into a united lattice of root and rock. Attempts to remove any one root invariably pulled on bone and matrix in other parts of the jacket. These attempts included cutting or trimming root material with utility knives, scissors, hand saws, oscillating and rotary cutoff saws. The friable nature of the fossil material resulted in breaking and crumbling in any place where roots contacted or passed through bones, and the tight web of vegetation transferred small vibrations throughout the block.

In this scenario, fire was likewise determined to be the safest solution for removal of plant, fossil, and rock from the field jacket. As matrix was removed with mechanical tools and roots were exposed, the Aim 'N Flame ${ }^{\circledR}$ lighter was used to burn away both small and large roots. Flame was applied carefully to control the temperature and rate of combustion. Smaller roots immediately burned away and did not remain on fire. Flame was applied for shorter periods of time to larger roots to ensure that the organic material did not continue to burn after the flame was removed.

Testing. Before being applied directly to areas of the jacket in close contact with fossils, this technique was first attempted with an experimenter's hand slipped between the jacket and non-bone bearing matrix to ensure that temperatures inside the block would not be high enough to cause dam- 
TABLE 1. Sample temperatures taken from interior/exterior surfaces $\left({ }^{\circ} \mathrm{C}\right) .{ }^{*}$ indicates time at which fire was extinguished.

\begin{tabular}{lccccc}
\hline & Torch test & Sample 1 & Sample 2 & Sample 3 & Sample Avg. \\
\hline 0 seconds & $25 / 25$ & $25 / 25$ & $24 / 24$ & $25 / 25$ & $25 / 25$ \\
30 seconds & $26 / 355$ & $32 / 184$ & $26 / 219$ & $31 / 191$ & $30 / 198$ \\
60 & $38 / 320$ & $43 / 200$ & $31 / 260$ & $32 / 252$ & $35 / 237$ \\
90 & $56 / 300$ & $42 / 175$ & $35 / 93^{*}$ & $40 / 70^{*}$ & $39 / 113$ \\
120 & $62 / 276$ & $36 / 80^{*}$ & $30 / 65$ & $35 / 60$ & $34 / 69$ \\
3 min & n/a & $43 / 55$ & $37 / 44$ & $37 / 50$ & $39 / 50$ \\
4 min & n/a & $45 / 57$ & $30 / 28$ & $35 / 47$ & $37 / 44$ \\
9 min & n/a & $31 / 43$ & $30 / 34$ & $27 / 37$ & $29 / 38$ \\
\hline
\end{tabular}

age through thermal shock (fracturing due to rapid change of temperature, like adding cold water to a hot glass baking dish) or discoloration due to scorching. Since temperatures inside the jacket did not have a perceptible adverse effect on our hand, it was determined that the method was safe enough to apply to fossil material.

Subsequent laboratory testing was conducted to determine temperature ranges during fire-aided field jacket removal. To establish maximum temperatures likely to be reached in a controlled laboratory environment, a $21 \times 15 \times 1.5 \mathrm{~cm}$ plaster and burlap panel was heated for two minutes with direct flame from a Bernzomatic ${ }^{\circledR}$ MAP/ Pro gas torch. Temperature measurements were taken with a Performance Tool W89721 infrared thermometer from the "exterior" and "interior" of the panel. To establish normal working temperatures while removing field jackets, three sample panels of field jacket (approximately $22 \mathrm{~cm} \mathrm{X} 15 \mathrm{~cm} \mathrm{X} 1.5$ $\mathrm{cm}$ ) consisting of three layers of burlap and plaster were prepared by scoring a $10 \mathrm{~cm}$ square area of the surface with a razor blade until burlap was exposed and surface temperatures were recorded. The scored $1.5 \mathrm{~cm}$ thickness represented the thickness at which fire was typically phased out in favor of peeling the remaining pliable layers of field jacket. Next, $5 \mathrm{~mL}$ of acetone was applied to the burlap and ignited, and temperatures were measured at $30,60,90,120,180,240$, and 540 seconds (Table 1). The burlap was allowed to burn until it naturally extinguished.

\section{RESULTS AND DISCUSSION}

MAP/Pro gas burns at a temperature of 2,054 ${ }^{\circ} \mathrm{C}$, so a test was conducted to establish the maximum temperature that a field jacket could reach in a "worst case" scenario due to misapplication of a torch. The direct application of flame from a torch raised the outer temperature of the sample panel to a maximum temperature of $355{ }^{\circ} \mathrm{C}$. The interior surface, which would be in direct contact with fossil material, reached $62{ }^{\circ} \mathrm{C}$ at two minutes when the torch was extinguished. Application of torch heat was halted after two minutes, because burlap fires always consumed available fuel and self-extinguished at or before two minutes of ignition. The highest exterior temperatures measured occurred at 30 seconds and dropped as heat transferred through the sample panel. Consequently, the highest interior temperatures were measured at two minutes of direct flame.

Samples tested under normal working conditions (igniting small $\sim 15 \times 15 \mathrm{~cm}$ patches of field jacket) reached an exterior maximum of $260{ }^{\circ} \mathrm{C}$ and maximum interior temperature of $45^{\circ} \mathrm{C}$. Temperature measurements continued until nine minutes after initial ignition, since this trial better reflected realistic conditions. Exterior temperatures rapidly dropped after the fire was extinguished. After nine minutes, all samples remained at elevated temperatures relative to start.

The use of fire during preparation allowed for the removal of a tightly conforming field jacket \#98104 (Figure 2A) and the removal of matrix from around and within root-invaded vertebrae in \#98011 (Figure 2B). Other Maevarano Formation field jackets prepared at DAK were similarly treated with one or both fire-based preparation methods with no damage to the fossils.

This method was later successfully applied during the preparation of MOR 1184, the holotype of Pristocosturion longipinnis, a Cretaceous sturgeon from the Judith River Formation of Montana. MOR 1184 was preserved inside the ribcage of a hadrosaurian dinosaur (Hilton and Grande, 2006), and a tightly conforming plaster and burlap cradle was tightly bound to the ventral surface of the specimen. The medial side of the ribcage, encapsulating the fish fossil, had been partially prepared, and gross preparation of the sturgeon had begun. 


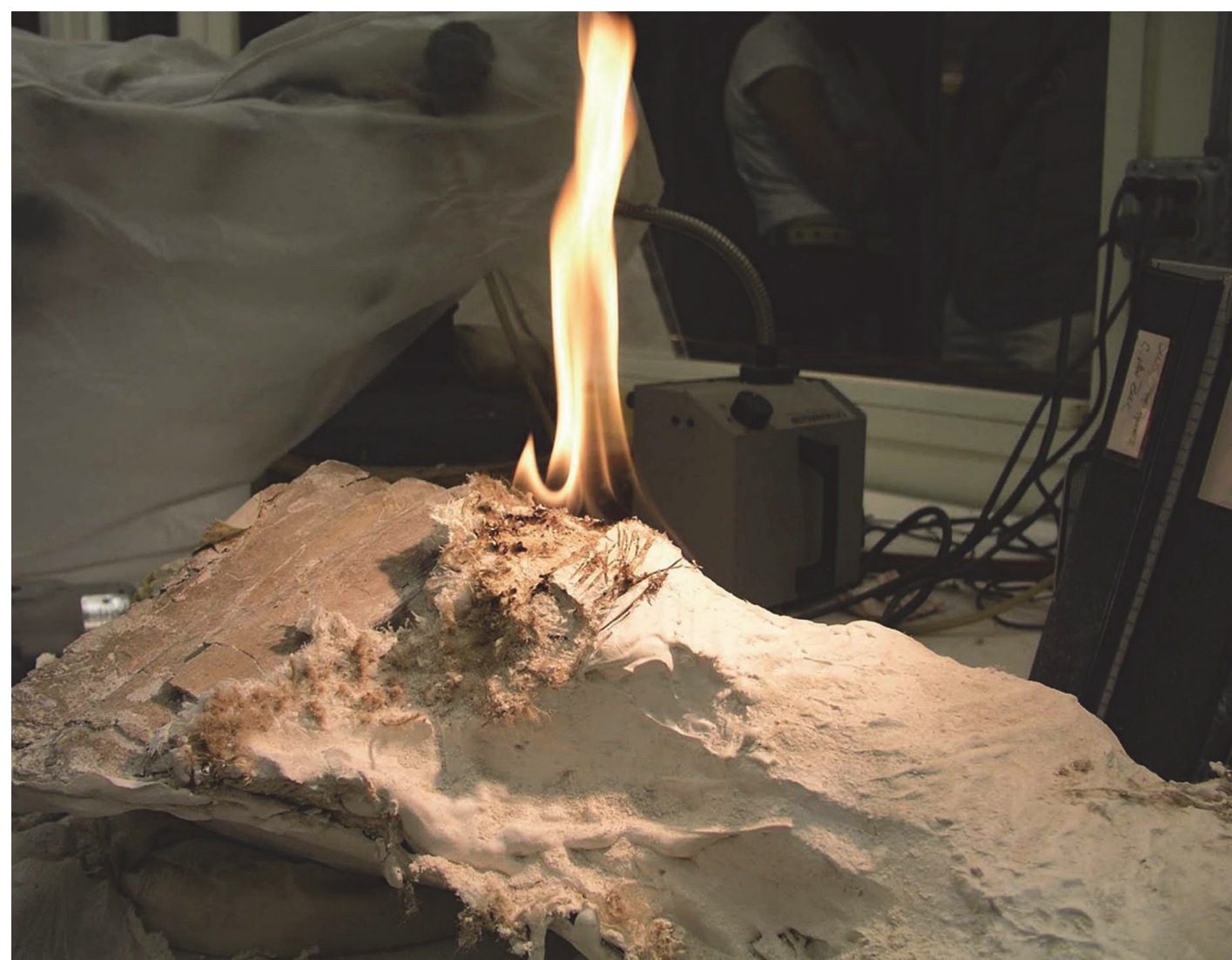

FIGURE 3. A plaster and burlap cradle containing MOR 1184 being burned away from the entrapped fossil.

Prior to further fine preparation of the delicate skeleton of the sturgeon (Van Beek and Brown, 2010) the plaster jacket had to be removed, and the fire technique was applied (Figure 3 ) to thin the plaster and burlap cradle. This method similarly allowed for the exposure of fossil material without mechanical damage to the bones within the block.

Fire was also used to remove modern vegetation in an articulated skeleton of the Late Triassic Chinle Formation aetosaur Scutarx deltatylus (PEFO 31217) collected from Petrified Forest National Park. PEFO 31217 was similarly invaded by a persistent root system in a highly friable specimen. This specimen was so poorly preserved that during excavation the majority of an ilium was damaged during high winds in the quarry, and at least one field jacket lacked the structural integrity to survive flipping, resulting in the destruction and loss of much of the trunk region. Even gentle brushing proved to be destructive in the field and laboratory, so plastic drinking straws and nasal aspirators were used to blow overlying sediment away from the bone surfaces, and PaleoBond Penetrant Stabilizer PB002 (Uncommon Conglomerates) cyanoacrylate adhesive was used as a consolidant (Parker, 2016). The combination of non-reversible cyanoacrylate adhesive and fragile fossil bones prevented the disarticulation of the specimen and three-dimensional preparation inthe-round, so the bones were exposed in situ within the field jacket.

The long wand of the Aim 'N Flame ${ }^{\circledR}$ lighter was critical to precise application of flame during removal of roots in all specimens, especially in recessed areas where matrix was removed from between bones. It also allowed the preparator to ignite solvent saturated burlap from a safer distance than would a conventional cigarette lighter or match. Several butane lighter manufacturers now offer products with flexible nozzles, which afford greater access to undercuts or pockets between bones that cannot be reached with a straight-wanded tool.

Safety. Safety of both workers and specimens is paramount during any fossil preparation or field activity. Field jacketing materials should be verified to ensure that they are non-toxic materials that will not create noxious fumes. Fire should only be used on jackets containing natural fabrics like burlap or cotton, and not synthetics like polyester foam or 
fabric. To ensure the safety of workers, standard precautions for use of open flame in the laboratory apply, which include adequate ventilation, proper Personal Protective Equipment (PPE) (e.g., Nomex fire resistant lab coat and gloves), and immediate access to an appropriately rated fire extinguisher. A bucket of playground sand, accessible in most fossil preparation labs, could be used to smother small, non-emergency fires that do not readily self-extinguish. However, we never encountered this circumstance. It is imperative that all flammable materials (including any containers of solvent) be moved clear of work surface prior to ignition. Long hair, jewelry, or loose-fitting clothing must be properly covered with PPE. A fire-resistant work surface (e.g., phenolic resin composite or epoxy laboratory bench) is strongly recommended.

Despite a common misperception that fossils are durable, "rock-like" objects, they are still subject to most of the same physical and chemical agents of deterioration common to natural history collections. These include effects of fire, like thermal shock and damage from smoke and soot (Fitzgerald, 1995; Knötschke et al, 2014; Brown, 2019). Benton and Reardon (2006) have demonstrated through field and laboratory tests that fossils can suffer negative effects from high heat during controlled burns and wildfires, and documented the temperatures at which damage from fire was evident. Nocera's (1955) experiments using flame applied directly to gypsum-covered fossils resulted in bone material spalling from the surface.

Additionally, chemicals applied to fossils are also affected by heat, most obviously flammable resins. Most archival adhesives exhibit thermoplastic properties (Davidson and Alderson, 2009; Fitzgerald, 1995) at elevated temperatures. However, the glass transition temperature $(\mathrm{Tg})$ of most common resins is closer to room temperature than many workers might realize. For example, the glass transition range of Vinac (McGean) B-15 is between $16-27{ }^{\circ} \mathrm{C}$, and a very hot day in the field even approaches the low bound of common higher $\mathrm{Tg}$ solution adhesives like Paraloid B72 $\left(40{ }^{\circ} \mathrm{C}\right)$ and Butvar B76 (48-55 ${ }^{\circ} \mathrm{C}$ ) (Elder et al., 1997). The Tg of Aron Alpha ${ }^{\circledR}$ Type 201 cyanoacrylate, $145^{\circ} \mathrm{C}$ (Aron Alpha, 2009), is well above the average internal temperature measured during this study. Thermoplastic properties of adhesives and the temperature ranges associated with them underscore the importance of documenting which consolidants and adhesives have already been applied to specimens in the laboratory and in the field.
Benton and Reardon (2006) noted that damage to fossils is possible due to elevated surface temperatures and contact with fuel. Types of damage that they identified include cracking and surface discoloration due to sooting, which they describe as the "interaction of combustion, smoke, and surface temperature" (Benton and Reardon, 2006:52). During their field testing under wildfire conditions, cracking of one sample $(n=20)$ took place at $61^{\circ} \mathrm{C}$. During laboratory conditions simulating low intensity wildfire conditions (average surface temperature of eight samples during two tests was $31.9{ }^{\circ} \mathrm{C}$ and $31.6{ }^{\circ} \mathrm{C}$ ), no discoloration or cracking of samples took place. During laboratory conditions simulating moderate wildfire conditions (average surface temperature of eight samples during two tests was $59.2{ }^{\circ} \mathrm{C}$ and $44.6{ }^{\circ} \mathrm{C}$ ), they noted that discoloration of one sample (of eight) took place at average temperatures in excess of $44.6{ }^{\circ} \mathrm{C}$. During laboratory conditions simulating high intensity wildfire conditions (average surface temperature of eight samples during two tests was $328.8^{\circ} \mathrm{C}$ and $492.3^{\circ} \mathrm{C}$ ), discoloration of seven of their eight samples took place. During laboratory conditions simulating moderate wildfire conditions when fossils were in direct contact with burning fuel (average surface temperature of $493.7^{\circ} \mathrm{C}$ ), discoloration of all four samples took place.

The highest internal jacket temperature produced during our laboratory tests was $45^{\circ} \mathrm{C}, 20^{\circ} \mathrm{C}$ below the lowest temperature under which fossils cracked in the Benton and Reardon tests. Although one sample in the Benton and Reardon laboratory test exhibited discoloration at $44.6{ }^{\circ} \mathrm{C}$, specimens within a field jacket do not come into contact with smoke or flame during plaster removal, and we do not anticipate that sooting would result using this method. However, when removing plant roots, care must be exercised during fire-aided preparation to prevent direct contact of flame with bone surfaces. It is also important to note that, in contrast to the 2006 Benton and Reardon study, the average temperatures measured during our experiments were taken from the inside of the field jacket sample, and not a fossil surface.

\section{CONCLUSION}

The best protection for safely recovering fossil material from the field is the ideal jacketing technique described by Adam Hermann more than a century ago:

A good collector's work always meets with the sympathy of the preparator, while on the other hand the work of a 
poor and careless collector creates ill feeling between the later and the preparator, not to speak of the damage done to specimens and the valuable time expended in the work of preparation.

In closing this subject I should also like to mention that it is a great fault on the part of some fossil collectors to free the bones too much from the matrix, for this weakens the specimens and makes them more difficult to transport. Unless the matrix is very soft and loose, as, for instance, sand, loose clay, etc., sufficient matrix should be left on the bones to insure safe transportation, and it always pays to ship a few extra pounds of rock, which can be easily removed in the laboratory, as this preserves the specimens intact. (Hermann, 1909:286)

On the occasions that Hermann's ideal conditions cannot be met, fire can be used safely to facilitate the preparation process in certain challenging specimens. Due to complications resulting from taphonomic and anthropogenic causes, the specimens described in this paper could not have been successfully exposed for research without employing fire to aid preparation in a controlled laboratory setting. Further, the implementation of these techniques prevented more substantial damage or complete destruction to fossil specimens. Even though fire introduces additional risk to workers during the preparation process, it is no greater than other use of open flame in laboratories and can be mitigated with proper PPE, engineering controls, and standard laboratory safety practices. Risk to specimens can likewise be mitigated by monitoring the internal temperatures of field jackets, fossils, and matrix; identifying materials present in field jacket construction; identifying any adhesives present and knowing the effects of increased temperature upon them; and preventing direct contact of fire with field jacket contents, particularly fossil material.

\section{ACKNOWLEDGMENTS}

The authors wish to thank W. Simpson for curation assistance and discussion, and C. Van Beek, J. McHugh, D. Wagner, K. Bader, W. Parker, and A. Marsh for discussion. J. McHugh/Museums of Western Colorado provided the photograph of MWC 9874. This manuscript was improved thanks to comments from two anonymous reviewers and handling editor R. Bicknell.

\section{REFERENCES}

Aron Alpha. 2009. Technical Data Sheet, Aron Alpha Type 201.

Auffenberg, W. 1967. What is a plaster jacket? The Plaster Jacket, 6:1-12.

Baird, D. 1978. The burnt dope technique and other intertidal ploys. The Chiseler, 1(2):16-17.

Bader, K.S., Hasiotis, S.T., and Martin, L.D. 2009. Application of forensic science techniques to trace fossils on dinosaur bones from a quarry in the Upper Jurassic Morrison Formation, Northeastern Wyoming. Palaios, 24:140-158. https://doi.org/10.2110/palo.2008.p08-058r

Benton, R. and Reardon, J. 2006. Fossils and fire: a study on the effects of fire on paleontological resources at Badlands National Park. Fossils from Federal Lands. New Mexico Museum of Natural History and Science Bulletin, 34:47-54.

Birthsiel, T. 2015. Plastered: An examination of unorthodox jacketing techniques. Journal of Vertebrate Paleontology, Abstracts of Papers, 35(supplement to Number 3):91.

Brinkman, P. 2010. The Second Jurassic Dinosaur Rush. The University of Chicago Press, Chicago. https://doi.org/10.7208/chicago/9780226074733.001.0001

Brown, M.A. 2019. Fossils, p. 864-865. In Elkin, L. and Norris, C.A. (eds.), Preventive Conservation: Collection Storage. Society for the Preservation of Natural History, American Institute for Conservation of Historic and Artistic Works, Smithsonian Institution, and The George Washington University Museum Studies Program, New York.

Brusatte, S. 2018. The Rise and Fall of the Dinosaurs, A New History of a Lost World, William Morrow, New York.

Camp, C. and Hanna, D. 1937. Methods in Paleontology. The University of California Press, Berkeley, California. 
Carrek, J. and Adams, S. 1969. Field extraction and laboratory preparation of fossil bones and teeth, using expanded polyurethane. Proceedings of the Geologists' Association, 80:81-89. https://doi.org/10.1016/s0016-7878(69)80019-2

Carroll, R.L., Belt, E.S., Dineley, D.L., Baird, D., and McGregor, D.C. 1972. p. 24-25. In Vertebrate Paleontology of Eastern Canada. Field Excursion A59 Guidebook, XXIV International Geological Congress, Montreal.

Cavigelli, J.P. 2008. On the use of plastic air conditioner filter media in plaster jackets for fossil collecting. Journal of Vertebrate Paleontology, Abstracts of Papers, 28(supplement to Number 3):62A.

Cheney, D. 1988. Techniques used in collecting fossil vertebrates on the Antarctic peninsula, $p$. 21-24. In Feldmann, R.M. and Woodburne, M. (eds.), Geology and Paleontology of Seymour Island, Antarctic Peninsula. Geological Society of America Memoir, 169. https://doi.org/ 10.1130/MEM169-p21

Curry Rogers, K. 2009. The postcranial anatomy of Rapetosaurus krausei (Sauropoda: Titanosauria). Journal of Vertebrate Paleontology, 29:1046-1086. https://doi.org/10.1671/039.029.0432

Curry Rogers, K. and Wilson, J.A. 2014. Vahiny depereti, gen. et sp. nov., a new titanosaur (Dinosauria, Sauropoda) from the Upper Cretaceous Maevarano Formation, Madagascar. Journal of Vertebrate Paleontology, 34:606-617. https://doi.org/10.1080/ 02724634.2013 .822874

Davidson, A. and Alderson, S. 2009. Adhesives in fossil preparation. p. 53-62. In Brown, M.A., Parker, W.G, and Kane, J.F. (eds.), Proceedings of the First Annual Fossil Preparation and Collections Symposium. Petrified Forest, Arizona.

Elder, A., Madsen, S., Brown, G., Herbel, C., Collins, C., Whelan, S., Wenz, C., Alderson, S., and Kronthal. L. 1997. Adhesives and consolidants in geological and paleontological conservation: A wall chart. Society for the Preservation of Natural History Collections Leaflets, 1(2):1-4.

Fitzgerald, G.R. 1995. Storage and Transport. In Collins, C. (ed.), Care and Conservation of Paleontological Material. Conservation and Museology Series, Butterworth-Heinemann, Oxford.

Francischini, H., Lucas, S.G., Dentzien-Dias, P., and Schultz, C.L. 2020. Recent root damages of fossilized vertebrate remains from New Mexico, USA. In Martínez, S., Rojas, A., and Cabrera, F. (eds.), Actualistic Taphonomy in South America. Topics in Geobiology, 48. Springer, Cham. https://doi.org/10.1007/978-3-030-20625-3_8

Grande, L. and Hilton, E. 2006. An exquisitely preserved skeleton representing a primitive sturgeon from the Upper Cretaceous Judith River Formation of Montana (Acipenseriformes: Acipenseridae: N. gen. and sp.). The Paleontological Society Memoir 65, Journal of Paleontology, 80(4, suppl.):1-39. https://doi.org/10.1666/05032.1

Harris, S., Dickinson, B., Murray D., Smith A., and McBrain N. 1983. Quest for Fire. Piece of Mind, Album. Capitol Records, Los Angeles.

Hermann, A. 1909. Modern laboratory methods in vertebrate paleontology. Bulletin of the American Museum of Natural History, 26:283-331.

Knötschke, N, Mastroianni, M., and Wings, O. 2014. A song of blasting and fire: Europasaurus holgeri. 74th Annual Meeting of the Society of Vertebrate Paleontology: Program and Abstracts, p. 160-161

Johnson, R. 1984. The uses of poly-foam as a field-jacketing material: Experiences at Dinosaur National Monument. Society of Vertebrate Paleontology News Bulletin 133:27.

Langston, Jr., W. 1948. Vertebrate paleontological field technique and its application to archaeological collecting. Bulletin of the Texas Archeological and Paleontological Society, 18:88-99.

Lawrence, D.R. 1979. Diagenesis of fossils—fossildiagenese. In Paleontology. Encyclopedia of Earth Science. Springer, Berlin, Heidelberg. https://doi.org/10.1007/3-540-31078-9_46

Munsell Color. 2009. Geological Rock-Color Chart: with Genuine Munsell Color Chips. Grand Rapids, Michigan, 9 pp.

Nocera, J. 1955. On the removal of gypsum from vertebrate fossils. Society of Vertebrate Paleontology News Bulletin, 44:19.

Parker, W. 2016. Osteology of the Late Triassic aetosaur Scutarx deltatylus (Archosauria: Pseudosuchia). PeerJ, 4:e2411. https://doi.org/10.7287/peerj.preprints.1924 
Rogers, R.R. 2005. Fine-grained debris flows and extraordinary vertebrate burials in the Late Cretaceous of Madagascar. Geology, 33:297-300. http://doi.org/10.1130/G21036.1

Tanke, D. 2014. Personal, historical and technical perspectives on the growing role of light and heavy industry on vertebrate palaeontology in Alberta, Canada. Alberta Palaeontological Society, Eighteenth Annual Symposium, Abstracts, pp. 49-50.

Van Beek, C. and Brown, M.A. 2010. Three dimensional preparation of a Late Cretaceous sturgeon from Montana: a case study. The Geological Curator, 9(3):149-153. 